Original Research Paper

\title{
Characterization of Flavor Properties of Sufu by HS- SPME/GC-MS, Electronic Nose and Electronic Tongue Combined with Multivariate Statistical Analysis
}

\author{
${ }^{1}$ Xiaoli Xi, ${ }^{1,2}$ Yanli Ma, ${ }^{2}$ Jingxuan Ke, ${ }^{1}$ Yinzhuang Wang, ${ }^{1}$ Xiaodong Gu, \\ ${ }^{1}$ Yaqiong Liu, ${ }^{1}$ Jianfeng Sun and ${ }^{1} \mathrm{Jianlou} \mathrm{Mu}$ \\ ${ }^{1}$ College of Food Science and Technology, Hebei Agricultural University, Baoding, China \\ ${ }^{2}$ Henan Key Laboratory of Industrial Microbial Resources and Fermentation Technology; Henan Key Laboratory of Zhang \\ Zhongjing Formulae and Herbs for Immunoregulation, Nanyang Institute of Technology, Nanyang, China
}

\begin{abstract}
Article history
Received: 23-07-2021

Revised: 29-10-2021

Accepted: 01-11-2021

Corresponding Author:

Yanli Ma

Henan Key Laboratory of Industrial Microbial Resources and Fermentation Technology; Henan Key Laboratory of Zhang Zhongjing Formulae and Herbs for Immunoregulation, Nanyang Institute of Technology, Nanyang, China Email: xuexi_myl@sina.com
\end{abstract}

\begin{abstract}
Flavor is the main quality characteristic of sufu. The flavor of different types of sufu varies greatly, which will affect the preference and selectivity of consumer for sufu. To explore the flavor characteristics and distinguishing methods in different types of sufu, the volatile flavor components and free amino acids of 5 kinds of commercial sufu were determined by HS-SPME/GC-MS and amino acid automatic analyzer, respectively. Moreover, the electronic nose and electronic tongue were used to distinguish the sufu samples. The results showed that a total of 71 volatile aroma compounds were identified, in which esters (28.43-79.17\%) were the main flavor substances. The total free amino acid contents in different types of sufu were at a range of $24.8-33.89 \mathrm{mg} / \mathrm{g}$. Bitter amino acids were dominant in all sufu (except GS). PCA of electronic nose and electronic tongue showed that the electronic nose can only distinguish the grey sufu, while the electronic tongue can effectively distinguish among types of sufu. PLS-DA based on aroma and taste substances showed that sufu can be distinguished. According to VIP, fifteen volatile flavor components and five taste amino acids could be used as the main different compounds of sufu. The research results pretended that HS-SPME/GC-MS, electronic tongue technology combined with multivariate statistical analysis method can effectively distinguish sufu. These findings will provide guiding significance to identify the types of sufu and consumers' purchase products and promote the development of sufu industry to a certain extent.
\end{abstract}

Keywords: Sufu, Volatile Flavor Components, Free Amino Acids, Electronic Nose, Electronic Tongue

\section{Introduction}

Sufu, a traditional Chinese fermented soybean product, is also known as Chinese cheese because its shape, fermentation and processing mechanism as well as texture are similar to cheese (Xie et al., 2018). Attributing to the delicious taste and unique flavor of sufu, it has been widely consumed in China as an appetizer for thousands of years. Its production usually involves four steps: (1) preparation of tofu; (2) preparation of pehtze with tofu cubes inoculated microorganisms; (3) brining of pehtze and (4) ripening. According to different color and flavor, sufu can be divided into four different types, i.e., red sufu, white sufu, grey sufu and other sufu (Han et al., 2004). During the fermentation process, protein, lipid, starch and other substances of raw materials can produce amino acids, esters, alcohols, aldehydes, acids and other flavor compounds via a series of biochemical pathways (Han et al., 2001, Xie et al., 2019a). In addition, amino acids can participate in the esterification and reduction reactions after deamination and decarboxylation and can also produce some flavor substances (Zhao et al., 2016). These flavor components (including aroma and taste) cooperate with each other and work together to give sufu unique flavor characteristics.

In recent years, with the continuous improvement of human health awareness, the development of new fermented food has become a trend. Subsequently, the types of sufu on the market are becoming more diverse. 
The flavor is important characteristic to evaluate food quality, which could affect the satisfaction of consumers (Liu et al., 2019). Therefore, it is necessary to explore the flavor characteristics and distinguishing methods of sufu in different types. At present, the research about the flavor of sufu has been reported. Liu et al. (2012) successfully applied Solid Phase Micro-Extraction (SPME) combined with Gas Chromatography-Mass Spectrometry (GC-MS) to identified 39 volatile flavors components of grey sufu, of which indole was the most important flavor substance. After, SPME/GCMS was also employed to analyze the volatile components of Kedong sufu during ripening. The results indicated that 75 compounds were identified, among which esters were the most abundant (Fan et al., 2019). Some studies have shown that free amino acids hydrolyzed by protein play an important role in taste characteristics of sufu. Moreover, statistical analysis methods have been widely used in various studies (Sunday, 2020, Umana et al., 2020). At the same time, researchers found that the combination of detection technology and statistical analysis method can achieve the effect of discrimination. Dong et al. (2019) successfully applied electronic nose, electronic tongue and HS-SPME/GC-MS data in combination with a Principal Component Analysis (PCA) to effectively distinguish roasted coffee beans with different drying methods. Electronic nose and electronic tongue are bionic detection methods simulating human olfactory and taste, which were widely used in the quality control and origin identification of some foods (Loutfi et al., 2015, Souayah et al., 2017). However, there are few reports on their application in the classification of sufu types.

The purpose of this study was to: (1) Evaluate the flavor properties of different types of sufu; (2) discriminate the type of sufu using electronic nose and electronic tongue; (3) Screen differential compounds by Partial Least Squares Discrimination Analysis (PLS-DA) based on the volatile components and free amino acids. These analyses are helpful to understand the flavor characteristics of sufu and provide basis for consumers to choose relevant products.

\section{Materials and Methods}

\section{Materials}

Five kinds of commercial sufu samples, including Red Sufu (RS), White Sufu (WS), Grey Sufu (GS), Low-Salt sufu (LS) and Oil Sufu (OS), were purchased from the local supermarket in Baoding, Hebei Province, China.

\section{Determination of Volatile Compounds}

Volatile compounds of sufu samples were analysed by HS-SPME/GC-MS according to the method of with some modifications (Liang et al., 2019). Briefly, $7.5 \mathrm{~g}$ uniform paste of each sufu sample was placed in a $20 \mathrm{~mL}$ headspace vial and mixed with $25 \mu \mathrm{L}$ of 3-octanol (300 $\mu \mathrm{g} / \mathrm{mL}$ in ethanol, internal standard). The vial was quickly sealed and then equilibrated for $10 \mathrm{~min}$ at $50^{\circ} \mathrm{C}$ in a water bath. Then, the divinylbenzene/carboxen/polydimethylsiloxane fibre (length: $1 \mathrm{~cm}$; df: 50/30 $\mu \mathrm{M}$; Supelco Ltd., Bellefonte, PA, USA) was exposed in the upper space of the headspace vial for $30 \mathrm{~min}$ at $50^{\circ} \mathrm{C}$. After that, the fiber was immediately injected into the $\mathrm{GC}$ injector to desorb the extractions at $250^{\circ} \mathrm{C}$ for $7 \mathrm{~min}$. The extractions were separated in the capillary column (HP-INNOWAX; $60 \mathrm{~m} \times 0.25 \mathrm{mM} \times$ $0.25 \mu \mathrm{M}$; J and W Science, Folsom, CA, USA). The oven temperature program was maintained at $35^{\circ} \mathrm{C}$ for $5 \mathrm{~min}$, then increased to $130^{\circ} \mathrm{C}$ at the speed of $4^{\circ} \mathrm{C} / \mathrm{min}$ and further increased to $200^{\circ} \mathrm{C}$ at the speed of $10^{\circ} \mathrm{C} / \mathrm{min}$. The carrier gas was purified helium $(99.999 \%)$ with a flow rate of $1 \mathrm{~mL} / \mathrm{min}$. The ionization energy was $70 \mathrm{eV}$ and the mass scan ranged from 40 to $350 \mathrm{~m} / \mathrm{z}$. The temperature of ion source and transmission line was 230 and $250^{\circ} \mathrm{C}$ respectively. The volatile components were identified by NIST 14 database and semi-quantified by internal standard.

\section{Determination of Free Amino Acids}

The free amino acids were determined using an automatic amino acid analyzer (L-8900; Hitachi, Tokyo, Japan), following the method of (Yoon et al., 2017). $2 \mathrm{~g}$ of the freeze-dried sample was mixed with $8 \mathrm{~mL}$ of $5 \%$ sulfosalicylic acid and shaken for $1 \mathrm{~h}$. Then, the mixture was centrifuged at $18000 \mathrm{rpm}$ for $30 \mathrm{~min}$ at $4^{\circ} \mathrm{C}$. The supernatant was successively filtered through $0.45 \mu \mathrm{m}$ and $0.22 \mu \mathrm{m}$ organic phase filters for analysis.

\section{Electronic Tongue Measurement}

The appropriate amount of sufu sample was placed in a $40 \mathrm{~mL}$ headspace bottle and the sample was tested after standing for $30 \mathrm{~min}$. The detection parameters are as follows: Carrier gas, clean air; gas flow rate, $1.0 \mathrm{~L} / \mathrm{min}$; cleaning flow, $6 \mathrm{~L} / \mathrm{min}$; test time, $60 \mathrm{~s}$; waiting time, $10 \mathrm{~s}$; detection temperature, $25^{\circ} \mathrm{C}$; injection gas volume, $10 \mathrm{~mL}$. Each sample was measured in five times.

\section{Electronic Nose Measurement}

Appropriate amount of sufu samples were weighed and extracted with ultrapure water and the same amount of sufu aqueous extract was taken for detection. The detection parameters are as follows: Maximum voltage, $10 \mathrm{~V}$; minimum voltage, $-10 \mathrm{~V}$; pulse interval, $100 \mathrm{~s}$; sensitivity, $10^{-4}$. Each sample was measured four times.

\section{Statistical Analysis}

Statistical analysis was performed using SPSS 22.0 (SPSS Inc., Chicago, IL, USA). Analysis of Variance (ANOVA) with Duncan's test was used to assess the significance $(\mathrm{P}<0.05)$. PCA and PLS-DA were undertaken using SIMCA 16.0.1 (Umetrics, Umea, Sweden). All data were expressed as mean \pm standard deviation. 


\section{Results}

\section{Volatile Compounds Analysis of Commercial Sufu by $H S$-SPME/GC-MS}

A total of 71 volatile compounds including alcohols (12), esters (26), aldehydes (5), ketones (3), phenols (4), acids (3), ethers (2), hydrocarbons (5), heterocycles (8) and other compounds (3) were identified and quantified from five kinds of commercial sufu and the detailed results were shown in Table1. In this study, alcohols and esters were the most abundant substances in all samples (except GS).

Alcohol compounds have special flavor and can also synthesize esters with organic acids, which has an important influence on the formation of unique flavor of sufu. Alcohols accounted for 44.11, 0.08, 40.41, 35.77 and $23.30 \%$ of the total concentrations in samples RS, GS, WS, LS and OS, respectively. Phenyl ethanol was identified in five kinds of sufu and its content in LS (7.16 $\mathrm{mg} / \mathrm{kg}$ ) was significantly higher than that of other sufu $(\mathrm{P}<0.05)$. The top component of alcohols in the RS, WS, LS and OS was ethanol and its content was 17.83-35.19 $\mathrm{mg} / \mathrm{kg}$. However, ethanol was not detected in GS.

Esters, the most important flavor constituents in sufu, are primarily produced by the esterification or alcoholysis and usually responsible for typical fruity and sweet aromas (Liu et al., 2004). The total content of ester was $270.11 \mathrm{mg} / \mathrm{kg}$ in GS, which was significantly higher than the other sufu samples $(\mathrm{P}<0.05)$. The higher content of esters in the RS, WS and LS were ethyl palmitate and ethyl octanoate which can give sufu dense ester, cream and brandy flavor. The highest content of esters in GS and OS was ethyl linoleate, which were 155.14 and $12.99 \mathrm{mg} / \mathrm{kg}$, respectively. The ethyl esters components of these five kinds of sufu were in the majority and the content were high. Only three kinds of methyl esters were identified and the content in OS was abundant.

Aldehydes and ketones may be derived from $\beta$-oxidation of fatty acids or catabolism of amino acids during fermentation (Yu et al., 2008). For example, benzaldehyde and phenylacetaldehyde can be produced by Phe catabolism and these two aldehydes are widely present in fermented soybean products ( $\mathrm{Li}$ et al., 2016). In this study, benzaldehyde was detected in all samples, ranging from 0.22 to $0.51 \mathrm{mg} / \mathrm{kg}$, while phenylacetaldehyde was only detected in LS $(0.44 \mathrm{mg} / \mathrm{kg})$. Three ketones were identified, namely camphor, 3-aminoacetophenone and 2-methyl-2cyclopentenone. Although the aromas of ketones are generally pleasant, they may contribute little to the flavor because of their low concentrations detected in sufu.

Phenolic compounds are associated with smoke and woody odors and previous research showed 2-methoxy-4vinylphenol can give soy sauce tar and smoke flavor (Parker et al., 2018). At the same time, 2-methoxy-4- vinylphenol is also the aroma active ingredient of Shaoxing rice wine (Chen et al., 2013). In this study, this substance was only detected in RS and LS. Phenol and 2methoxy-3-(2-propenyl) phenol were higher in the identified phenolic compounds. The content of phenol in GS $(8.69 \mathrm{mg} / \mathrm{kg})$ was significantly higher than that in other sufu $(\mathrm{P}<0.05)$.

Acids are important precursors for the synthesis of esters, aldehydes and other compounds, which can be produced by long-chain fatty acid decomposition, amino acid degradation and microbial metabolism (Peng et al., 2014). The content of acids in GS ( $40.37 \mathrm{mg} / \mathrm{kg}$ ) was the highest and butyric acid accounted for about $60.94 \%$ of the total acid compounds. Butyric acid has cheese and creamy flavor at low concentrations, but it has strong stink at high concentrations. A trace amount of propionic acid was detected in GS, WS and LS, while acetic acid was the most abundant acid in WS and OS.

In addition, ethers, hydrocarbons and other compounds were identified in various types of sufu. 2(2-ethoxyethoxy) - ethanol and estragole were only identified in WS and OS and the content of estragole in WS was significantly higher than that in $\mathrm{RS}(\mathrm{P}<0.05)$. Hydrocarbon compounds have higher flavor threshold, so they have little effect on sufu flavor. Styrene and anethole shared in five kinds of sufu and the content of anethole in RS and WS were higher, 14.01 and 12.38 $\mathrm{mg} / \mathrm{kg}$, respectively. Dimethyl trisulfide, butyramide and high concentration of indole $(18.70 \mathrm{mg} / \mathrm{kg})$ were also identified in GS, which played an important role in the formation of sufu flavor.

\section{Analysis of Free Amino Acids}

Umami taste is described as brothy, savory or meaty taste sensation (Thammarongtham et al., 2001). Glu, Asp and their corresponding salts are important sources of umami. The salt added during the preparation of sufu will form sodium ammonia with Glu, thereby enhancing the umami taste. In addition, some ions can also affect the taste (Nkansah et al., 2019, Durguti et al., 2020). The contents of Glu in WS, LS and OS were $3.96,3.93$ and $3.84 \mathrm{mg} / \mathrm{g}$, respectively, with no significant difference $(\mathrm{P}>0.05)$. However, Asp contents in these three kinds of sufu were significantly different $(\mathrm{P}<0.05)$. The content of Asp in WS was the highest $(2.45 \mathrm{mg} / \mathrm{g})$, followed by OS $(2.28 \mathrm{mg} / \mathrm{g})$. The content of umami amino acids in GS $(0.38 \mathrm{mg} / \mathrm{g})$ was the lowest. In terms of the sweet amino acids, the content of Ala was relatively high, ranged from 1.54 to 3.05 $\mathrm{mg} / \mathrm{g}$. Moreover, Gly also induced strong sweetness and its content was the highest in LS. Ser was not detected in WS. The whole taste of sufu was also affected by the threshold of taste active compounds. Although tasteless amino acids do not have taste activity, they enhance the taste intensity of other components. 
Table 1: Volatile flavor components and content from five kinds of sufu

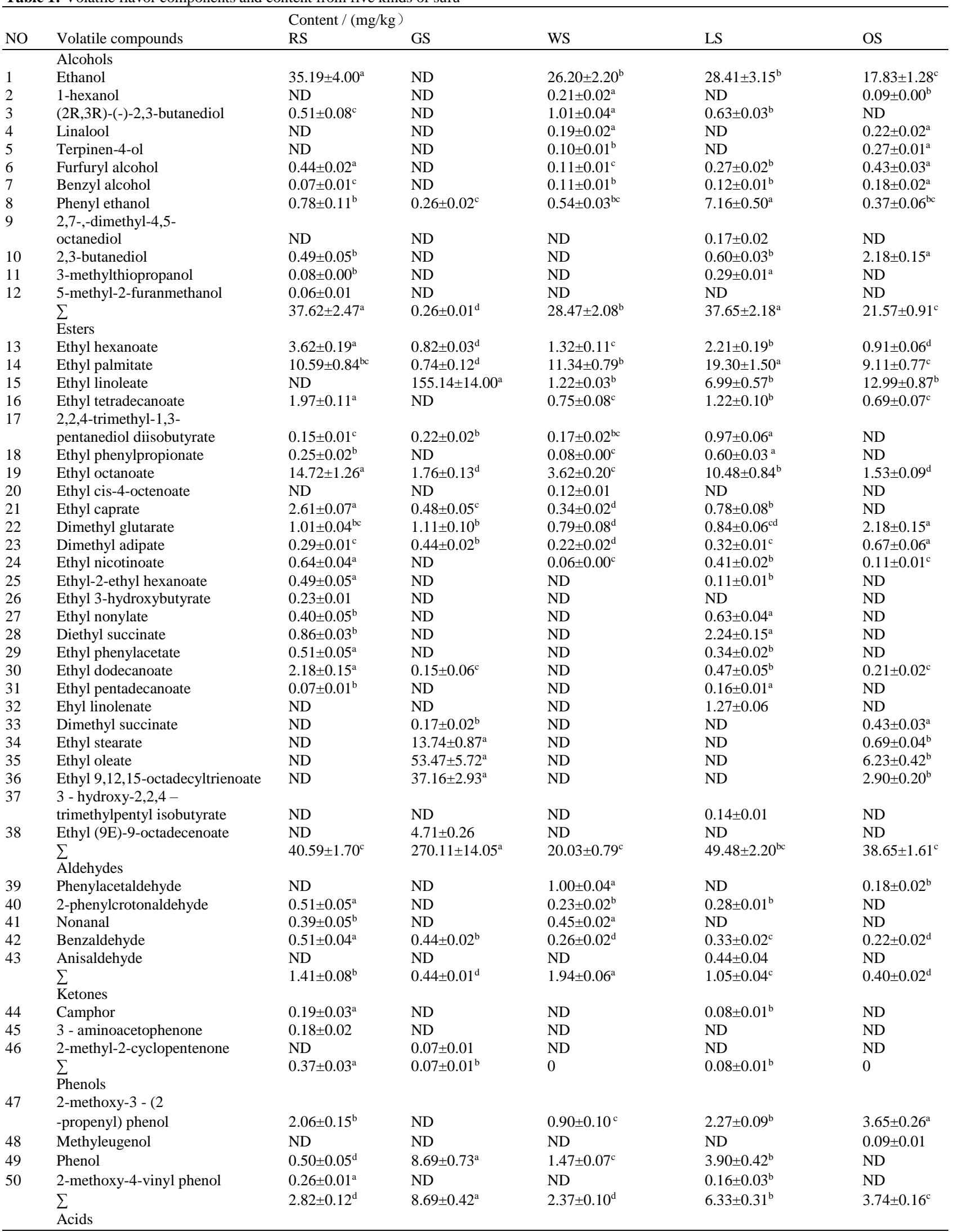




\begin{tabular}{|c|c|c|c|c|c|c|}
\hline 51 & Propionic acid & ND & $2.81 \pm 0.09^{\mathrm{a}}$ & $0.21 \pm 0.02^{\mathrm{c}}$ & $0.50 \pm 0.05^{\mathrm{b}}$ & ND \\
\hline 52 & Butyric acid & ND & $24.60 \pm 2.20^{\mathrm{a}}$ & $1.70 \pm 0.08^{\mathrm{b}}$ & ND & $0.38 \pm 0.03^{\mathrm{b}}$ \\
\hline 53 & Acetic acid & ND & $12.96 \pm 0.85^{\mathrm{a}}$ & ND & $7.88 \pm 0.52^{\mathrm{b}}$ & $4.41 \pm 0.37^{\mathrm{c}}$ \\
\hline 54 & 2-(2-ethoxyethoxy) - ethanol & ND & ND & $0.09 \pm 0.01^{\mathrm{a}}$ & ND & $0.08 \pm 0.01^{\mathrm{a}}$ \\
\hline \multirow[t]{3}{*}{55} & Estragole & ND & ND & $0.98 \pm 0.10^{\mathrm{a}}$ & ND & $0.55 \pm 0.10^{\mathrm{b}}$ \\
\hline & $\sum$ & 0 & 0 & $1.07 \pm 0.06^{\mathrm{a}}$ & 0 & $0.63 \pm 0.06^{\mathrm{b}}$ \\
\hline & Hydrocarbons & & & & & \\
\hline 56 & Styrene & $0.54 \pm 0.05^{\mathrm{a}}$ & $0.19 \pm 0.01^{\mathrm{d}}$ & $0.27 \pm 0.02^{\mathrm{c}}$ & $0.40 \pm 0.06^{\mathrm{b}}$ & $0.35 \pm 0.04^{\mathrm{b}}$ \\
\hline 57 & Tetradecane & ND & ND & ND & $0.08 \pm 0.00$ & ND \\
\hline 58 & Anethole & $0.19 \pm 0.03^{\mathrm{e}}$ & $0.64 \pm 0.04^{\mathrm{c}}$ & $12.38 \pm 1.11^{\mathrm{b}}$ & $0.39 \pm 0.04^{\mathrm{d}}$ & $14.01 \pm 0.80^{\mathrm{a}}$ \\
\hline 59 & 1,3,5-trimethylbenzene & ND & $0.10 \pm 0.01$ & ND & ND & ND \\
\hline \multirow[t]{3}{*}{60} & (Z)-1-methoxy-4- & & & & & \\
\hline & (1-propenyl) - benzene & $\mathrm{ND}$ & $\mathrm{ND}$ & ND & $\mathrm{ND}$ & $4.65 \pm 0.40$ \\
\hline & $\sum$ & $0.73 \pm 0.05^{\mathrm{c}}$ & $0.93 \pm 0.03^{\mathrm{c}}$ & $12.65 \pm 0.65^{\mathrm{b}}$ & $0.87 \pm 0.06^{\mathrm{c}}$ & $19.01 \pm 0.72^{\mathrm{a}}$ \\
\hline 61 & 2-pentylfuran & 1. $50 \pm 0.20^{\mathrm{a}}$ & $0.35 \pm 0.04^{\mathrm{e}}$ & $0.66 \pm 0.04^{\mathrm{d}}$ & $1.03 \pm 0.04^{\mathrm{b}}$ & $0.84 \pm 0.06^{\mathrm{c}}$ \\
\hline 62 & Indole & ND & $18.70 \pm 1.26^{\mathrm{a}}$ & $0.73 \pm 0.08^{b}$ & ND & $1.86 \pm 0.11^{\mathrm{b}}$ \\
\hline 63 & Naphthalene & ND & $0.18 \pm 0.02^{\mathrm{a}}$ & $0.20 \pm 0.02^{\mathrm{a}}$ & $0.17 \pm 0.03^{\mathrm{a}}$ & ND \\
\hline 64 & 2-methylnaphthalene & ND & ND & $0.07 \pm 0.01$ & ND & ND \\
\hline 65 & 1,6-dimethylnaphthalene & $0.13 \pm 0.00$ & ND & ND & ND & ND \\
\hline 66 & 2,6-dimethylpyrazine & ND & ND & $0.35 \pm 0.03$ & ND & ND \\
\hline 67 & 2,3,5-trimethylpyrazine & ND & ND & ND & $0.23 \pm 0.02$ & ND \\
\hline \multirow[t]{3}{*}{68} & 2-acetylpyrrole & ND & ND & ND & ND & $0.97 \pm 0.08$ \\
\hline & $\sum$ & $1.63 \pm 0.12^{\mathrm{c}}$ & $19.23 \pm 0.76^{\mathrm{a}}$ & $2.01 \pm 0.10^{\mathrm{c}}$ & $1.43 \pm 0.09^{c}$ & $3.67 \pm 0.14^{\mathrm{b}}$ \\
\hline & Others & & & & & \\
\hline 69 & Azulene & $0.11 \pm 0.02^{\mathrm{a}}$ & ND & ND & ND & $0.12 \pm 0.01^{\mathrm{a}}$ \\
\hline 70 & Dimethyl trisulfide & ND & $0.20 \pm 0.02$ & ND & ND & ND \\
\hline \multirow[t]{3}{*}{71} & Butyramide & ND & $0.86 \pm 0.05$ & ND & ND & ND \\
\hline & $\sum$ & $0.11 \pm 0.01^{\mathrm{b}}$ & $1.06 \pm 0.04^{\mathrm{a}}$ & 0 & 0 & $0.12 \pm 0.01^{\mathrm{b}}$ \\
\hline & Total & $85.28 \pm 4.57^{\mathrm{c}}$ & $341.16 \pm 17.15^{\mathrm{a}}$ & $70.45 \pm 3.90^{\mathrm{c}}$ & $105.27 \pm 5.17^{\mathrm{bc}}$ & $92.58 \pm 3.86^{\mathrm{c}}$ \\
\hline
\end{tabular}

a, b, c, d, e Different letters in the same row indicate statistical differences at the 0.05 level according to Duncan test. ND, not detect

\section{Analysis of Electronic Nose}

PCA was used as a method to reduce the dimensionality of the data in multivariate analysis, which could explain the maximum variance with the least principal component. Generally, the greater cumulative contribution rate of principal component, the more effective it was to reflect the information of original data (Zheng et al., 2013). PCA was applied on the data set obtained by the electronic nose and the results were shown in Fig. 1. The cumulative contribution rate of the principal components PC1 $(65.9 \%)$ and PC2 (16.9\%) was $85.6 \%$, which can basically represent the information of samples. The overlap and crossover among RS, WS, LS and OS samples were observed in Fig. 1, indicating similar odor characteristics of these sufu samples. Meanwhile, it also showed that PCA combined with electronic nose cannot distinguish these four types of sufu. The GS sample was divided into one area separately without overlap with other sufu, indicating that the odor components of GS sample were quite different from other samples. In short, the PCA combined with electronic nose was more suitable to identify the types of GS.

\section{Analysis of Electronic Tongue}

The data collected by the electronic tongue were also used to perform PCA and the results were shown in Fig. 2. The accumulated variance contribution rate of the first two principal components was $95.96 \%$ (PC1 and $\mathrm{PC} 2$ represented 92.10 and $3.86 \%$ of the total variance, respectively), indicating that the principal components PC1 and PC2 could explain most of the information of samples. GS were located in the second quadrant, which were far from other types of sufu, suggesting that there was a remarkable difference between GS and other sufu samples. It can be observed that the samples were divided into five groups without overlapping. Therefore, the electronic tongue can generally distinguish different kinds of sufu samples.

\section{Analysis of Volatile Flavor Components and Free Amino Acids in Sufu Using PLS-DA}

PLS-DA, a multivariate statistical method widely used for classification, can better distinguish differences between groups. In addition, the potentially differential compounds can be screened from Variables Important in the Projection (VIP) values. Generally, the compounds with VIP values>1 were essential for distinguishing between different kinds of sufu samples.

PLS-DA based on volatile flavor components was conducted and results were shown in Fig. 3 and 4. The PLS-DA score plot showed clear discrimination among different kinds of sufu samples. The RS and LS samples were located to the lower right of the X-axis, while the WS and OS samples were located to the upper left of the X-axis. For electronic nose analysis, the samples of RS, LS, OS and WS all clustered in the 
lower right side of PCA diagram, which were not obvious distinction between each other. However, five kinds of sufu could be effectively distinguished by PLS-DA. This is mainly because the former relies on the response of the sensor to a certain category of flavor components, while the latter mainly depends on the specific components in sufu.

Based on the standard of VIP $>1$, it can be found that nonanal, phenyl ethanol, 2,2,4-trimethyl-1,3pentanediol diisobutyrate and anisaldehyde had a great contribution to the difference of the sufu samples. Therefore, these substances were used as differential components in various sufu. In addition, ethyl palmitate, furfuryl alcohol, 3-methylthiopropanol, ethyl caprate, ethyl dodecanoate, diethyl succinate, dimethyl adipate, dimethyl glutarate, estragole, 2methoxy-3 - (2-propenyl) phenol and azulene also affected the classification of sufu.
PLS-DA based on free amino acids was performed and results were shown in Fig. 5 and 6. According to Fig. 5, the five kinds of sufu were all distributed in the $95 \%$ confidence interval and different sufus can be well distinguished. The GS and WS samples were located to the second quadrant and the fourth quadrant, respectively. As shown in Table 2, the content of umami amino acids in WS was the highest and that in GS were the lowest. Moreover, there was no significant difference in the total content of sweet amino acids between WS and GS, so as the content of bitter amino acids $(\mathrm{P}<0.05)$. In addition, the difference of tasteless amino acids in these two sufus was mainly reflected in the high content of Lys in WS samples. Therefore, the distribution characteristics of WS and GS on the score plot may be related to Asp, Glu and Lys. As shown in Fig. 6, the VIP values of Met, Phe, Ser, Tyr and Lys were all greater than 1 , which showed that these amino acids could be used as differential compounds in various sufu.

Table 2: Composition and content of free amino acids from five kinds of sufu

\begin{tabular}{|c|c|c|c|c|c|}
\hline \multirow[b]{2}{*}{ Amino acids } & \multicolumn{5}{|c|}{ Content (mg/g) } \\
\hline & RS & GS & WS & LS & OS \\
\hline \multicolumn{6}{|l|}{ umami amino acids } \\
\hline Aspartic acid (Asp) & $1.67 \pm 0.02^{\mathrm{d}}$ & $0.16 \pm 0.01^{\mathrm{e}}$ & $2.45 \pm 0.03^{\mathrm{a}}$ & $1.75 \pm 0.04^{\mathrm{c}}$ & $2.28 \pm 0.04^{\mathrm{b}}$ \\
\hline Glutamate (Glu) sweet amino acids & $3.56 \pm 0.03^{\mathrm{b}}$ & $0.22 \pm 0.03^{\mathrm{c}}$ & $3.96 \pm 0.17^{\mathrm{a}}$ & $3.93 \pm 0.15^{\mathrm{a}}$ & $3.84 \pm 0.12^{\mathrm{a}}$ \\
\hline Threonine (Thr) & $1.05 \pm 0.01^{\mathrm{c}}$ & $0.03 \pm 0.00^{\mathrm{d}}$ & $1.77 \pm 0.04^{\mathrm{a}}$ & $1.26 \pm 0.03^{\mathrm{b}}$ & $1.23 \pm 0.03^{\mathrm{b}}$ \\
\hline Glycine (Gly) & $1.06 \pm 0.01^{\mathrm{d}}$ & $0.07 \pm 0.00^{\mathrm{e}}$ & $1.13 \pm 0.02^{\mathrm{c}}$ & $1.22 \pm 0.02^{\mathrm{a}}$ & $1.16 \pm 0.01^{\mathrm{b}}$ \\
\hline Serine (Ser) bitter amino acids & $1.35 \pm 0.03^{\mathrm{b}}$ & $0.24 \pm 0.01^{\mathrm{d}}$ & ND & $0.81 \pm 0.01^{\mathrm{c}}$ & $1.64 \pm 0.02^{\mathrm{a}}$ \\
\hline Valline (Val) & $2.79 \pm 0.03^{\mathrm{e}}$ & $5.27 \pm 0.20^{\mathrm{a}}$ & $3.99 \pm 0.02^{\mathrm{b}}$ & $3.11 \pm 0.10^{\mathrm{d}}$ & $3.35 \pm 0.08^{c}$ \\
\hline Phenylalanine (Phe) & $3.69 \pm 0.15^{\mathrm{b}}$ & $3.39 \pm 0.12^{\mathrm{c}}$ & $2.67 \pm 0.04^{\mathrm{d}}$ & $4.03 \pm 0.20^{\mathrm{a}}$ & $2.61 \pm 0.05^{\mathrm{d}}$ \\
\hline Methionine (Met) & $1.46 \pm 0.05^{\mathrm{a}}$ & $0.91 \pm 0.02^{\mathrm{e}}$ & $1.27 \pm 0.03^{\mathrm{b}}$ & $1.00 \pm 0.04^{\mathrm{d}}$ & $1.20 \pm 0.03^{\mathrm{c}}$ \\
\hline Isoleucine (Ile) & $1.80 \pm 0.10^{\mathrm{c}}$ & $3.18 \pm 0.12^{\mathrm{a}}$ & $2.07 \pm 0.02^{\mathrm{b}}$ & $1.82 \pm 0.05^{\mathrm{c}}$ & $1.79 \pm 0.04^{\mathrm{c}}$ \\
\hline Leucine (Leu) & $3.14 \pm 0.09^{\mathrm{cd}}$ & $4.87 \pm 0.17^{\mathrm{a}}$ & $3.68 \pm 0.03^{\mathrm{b}}$ & $3.31 \pm 0.10^{\mathrm{c}}$ & $3.10 \pm 0.12^{\mathrm{d}}$ \\
\hline Histidine (His) & $0.25 \pm 0.01^{\mathrm{d}}$ & $0.02 \pm 0.00^{\mathrm{e}}$ & $0.79 \pm 0.01^{\mathrm{a}}$ & $0.32 \pm 0.00^{\mathrm{c}}$ & $0.72 \pm 0.00^{\mathrm{b}}$ \\
\hline Tyrosine (Tyr) & $1.08 \pm 0.01^{\mathrm{d}}$ & $1.58 \pm 0.02^{\mathrm{b}}$ & $2.01 \pm 0.03^{\mathrm{a}}$ & $1.14 \pm 0.03^{\mathrm{c}}$ & $0.89 \pm 0.01^{\mathrm{e}}$ \\
\hline Proline (Pro) & $2.74 \pm 0.04^{\mathrm{a}}$ & ND & $1.99 \pm 0.04^{\mathrm{d}}$ & $2.35 \pm 0.04^{\mathrm{b}}$ & $2.26 \pm 0.04^{\mathrm{c}}$ \\
\hline Lysine (Lys) & $1.36 \pm 0.05^{\mathrm{d}}$ & $1.39 \pm 0.02^{\mathrm{cd}}$ & $4.05 \pm 0.20^{\mathrm{a}}$ & $1.49 \pm 0.02^{\mathrm{c}}$ & $2.80 \pm 0.12^{\mathrm{b}}$ \\
\hline Cysteine (Cys) & $0.27 \pm 0.01^{\mathrm{d}}$ & $0.42 \pm 0.02^{\mathrm{a}}$ & $0.34 \pm 0.00^{\mathrm{b}}$ & $0.26 \pm 0.01^{\mathrm{d}}$ & $0.30 \pm 0.02^{\mathrm{c}}$ \\
\hline total free amino acid & $28.84 \pm 0.66^{\mathrm{c}}$ & $24.80 \pm 0.79^{d}$ & $33.89 \pm 0.52^{\mathrm{a}}$ & $29.75 \pm 0.78^{c}$ & $30.84 \pm 0.80^{\mathrm{bc}}$ \\
\hline
\end{tabular}

a, b, c, d, e Different letters in the same row indicate statistical differences at the 0.05 level according to Duncan test. ND, not detect

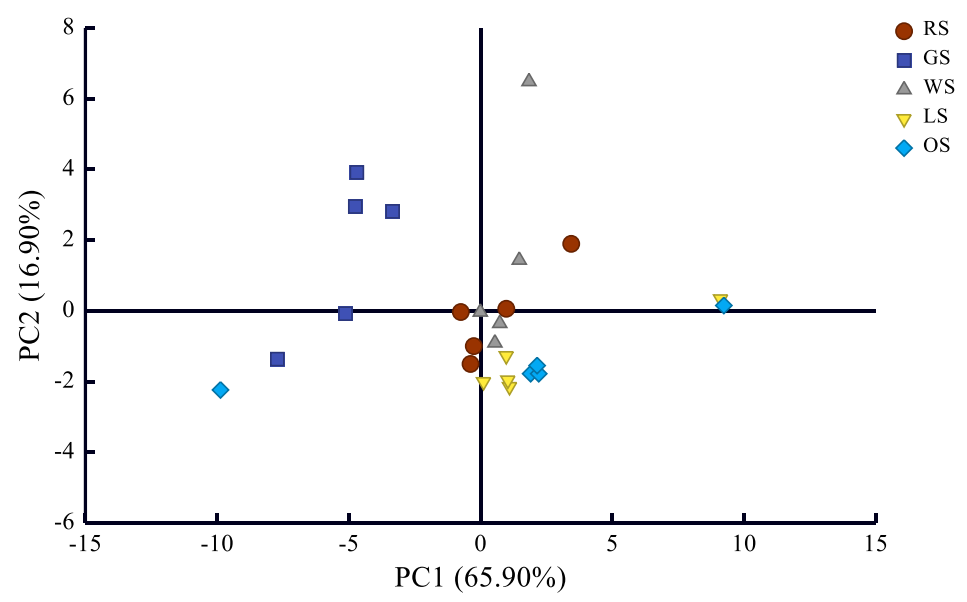

Fig. 1: Electronic nose PCA discrimination of five kinds of sufu 


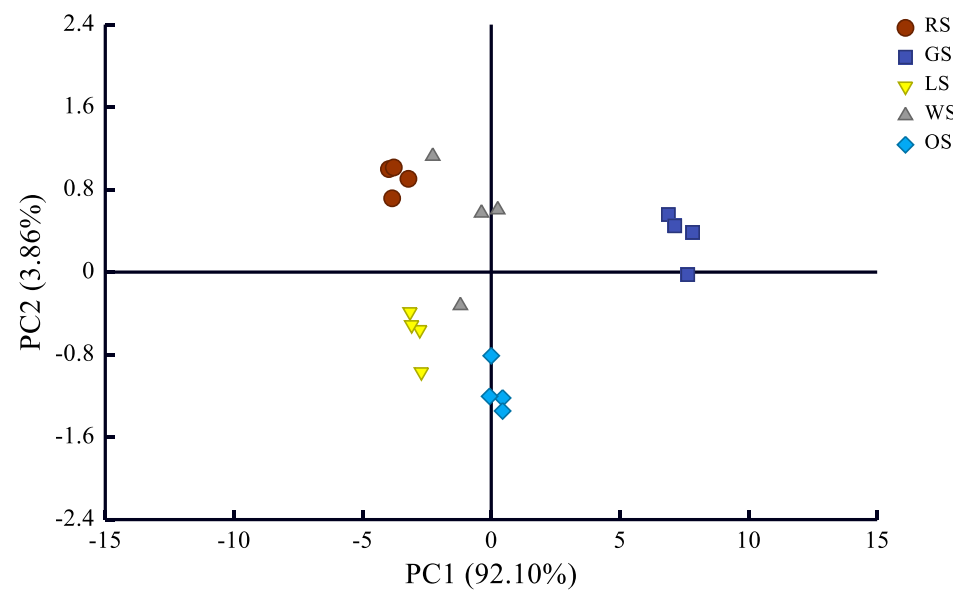

Fig. 2: Electronic tongue PCA discrimination of five kinds of sufu

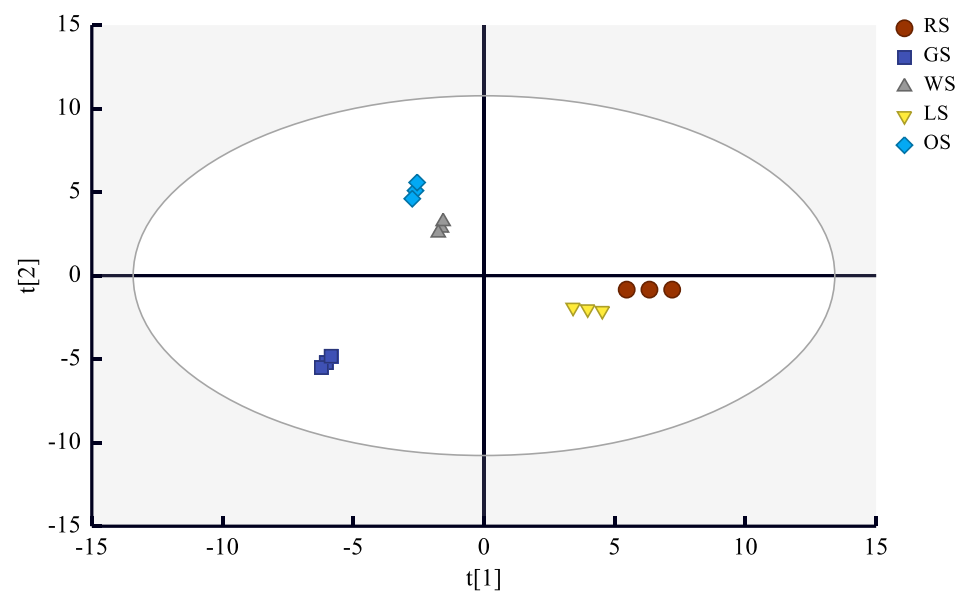

Fig. 3: The score plot of PLS-DA based on volatile flavor components

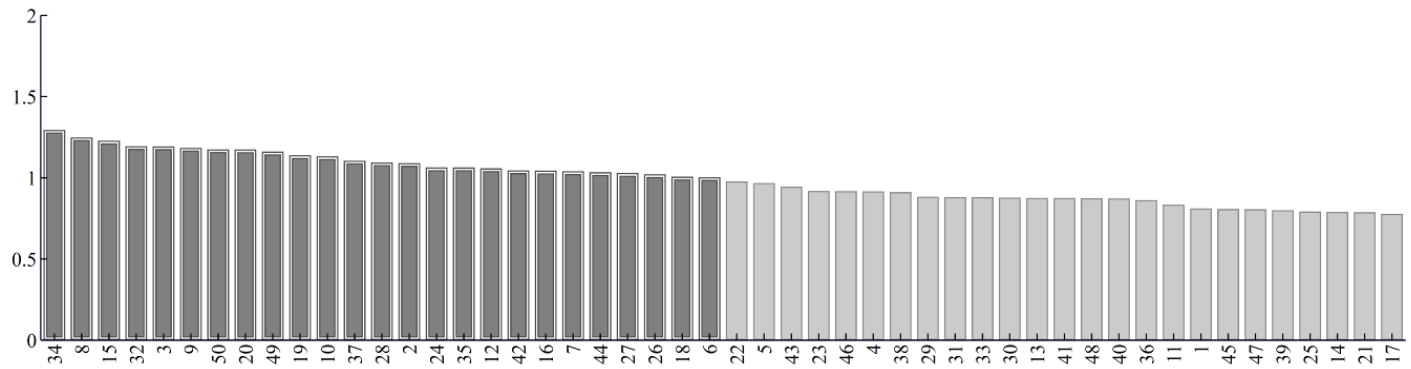

Fig. 4: Distribution of VIP forecast values of PLS-DA (1. Ethanol; 2. 1-hexanol; 3. (2R, 3R) - (-) -2,3-butanediol; 4. Linalool; 5. Terpinen-4-ol; 6. Furfuryl alcohol; 7. Benzyl alcohol; 8. Phenyl ethanol; 9. 2,3-butanediol; 10. 3-methylthiopropanol; 11. Ethyl caprate; 12. Ethyl palmitate; 13. Ethyl linoleate; 14. Ethyl tetradecanoate; 15. 2,2,4 - trimethyl-1,3 - pentanediol diisobutyrate; 16.3-Ethyl phenylpropionate; 17. Ethyl octanoate; 18. Ethyl caprate; 19. Dimethyl glutarate; 20. Dimethyl adipate; 21. Ethyl nicotinoate; 22. Ethyl-2-ethyl hexanoate; 23. Ethyl nonylate; 24. Diethyl succinate; 25. Ethyl phenylacetate; 26. Ethyl dodecanoate; 27. Ethyl pentadecanoate; 28. Dimethyl succinate; 29. Ethyl stearate; 30. Ethyl oleate; 31. Ethyl 9,12,15octadecyltrienoate; 32. Anisaldehyde; 33. 2- phenylcrotonaldehyde; 34. Nonanal; 35. Benzaldehyde; 36. Camphor; 37. 2methoxy-3- (2-propenyl) phenol; 38. Phenol; 39. 2-methoxy-4-vinylphenol; 40. Propionic acid; 41. Butyric acid; 42. Acetic acid; 43. 2-(2-ethoxyethoxy) - ethanol; 44. Estragole; 45. Styrene; 46. Anethole; 47. 2-pentylfuran; 48.Indole; 49. Naphthalene; 50. azulene. Dark gray represents VIP $>1$ ) 


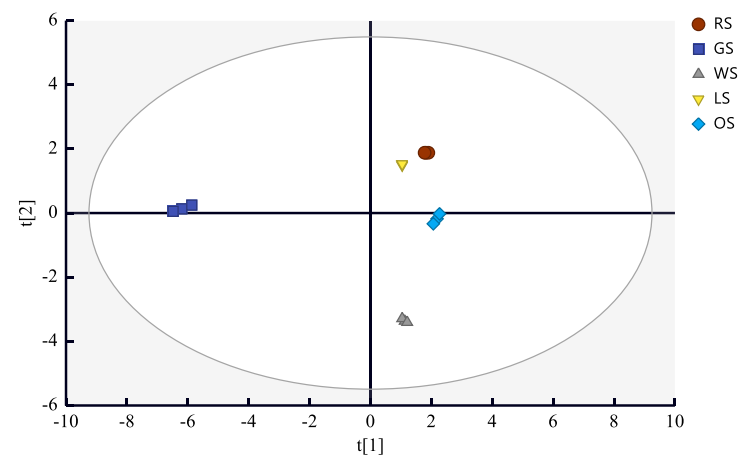

Fig. 5: The score plot of PLS-DA based on free amino acids

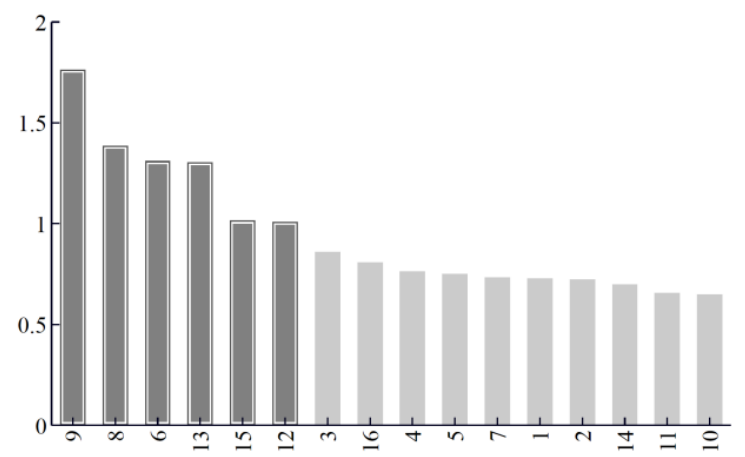

Fig. 6: Distribution of VIP forecast values of PLS-DAbased on free amino acids (1. Asp; 2. Glu; 3. Thr; 4. Gly; 5. Ala; 6. Ser; 7. Val; 8. Phe; 9. Met; 10. Ile; 11. Leu; 12. His; 13. Tyr; 14. Pro; 15. Lys; 16. Cys. Dark gray represents VIP > 1)

\section{Discussion}

In this study, the types and contents of the volatile compounds in different sufu were various, but alcohols and esters were dominant in all samples (except GS). The results were similar to the report of Chung (2000). Moy et al. (2012) detected 52 volatile flavor components in enzymeripened sufu, which was lower than that detected in this study. This is mainly caused by different processing technologies. Enzyme-ripened sufu was fermented with rice-soybean koji mash, while the sufu in this study was fermented with Mucor. The content of ethanol in GS was significantly lower than that in other sufu, which may be mainly related to the production technology. Generally, the dressing mixtures added to RS and WS during the post-fermentation contain alcohol, while the most ingredients in seasoning mixtures of GS are yellow serofluid. Hwan and Chou (1999) explored the effect of ethanol addition during post-fermentation period on volatile components of sufu and the results indicated that only a small amount of alcohols were produced by multiple enzymes during ripening and most alcohols were added by exogenous sources. Phenyl ethanol, an alcohol shared in all sufu, can be formed by phenylalanine catabolism, which provided rose-like sweet floral flavor for sufu (Ardo, 2006). In addition, the methyl ester compounds in OS were more abundant. Wei et al. (2021) also detected methyl esters in oil sufu and the main component being methyl salicylate. Sufu also contains ingredients beneficial to human health. For example, Ji (2020) in the study about volatile components in commercial sufu mentioned that ethyl linoleate can reduce cholesterol and blood lipids, with fewer side effects than linoleic acid with the same effect.

The concentration of aldehydes in the tested samples was lower, which may be attributed to the chemical properties of aldehydes themselves. Their properties are relatively reactive and they are easily oxidized to corresponding acids or reduced to corresponding alcohols during fermentation (Smit et al., 2009). 2-methoxy-4vinylphenol is the aroma active ingredient of Shaoxing rice wine (Chen et al., 2013). At the same time, rice wine can also be used as the soup component of post fermentation. So, 2-methoxy-4-vinyl phenol may be derived from the mixed soup and the thermal degradation of lignoside or ferulic acid (Wang et al., 2019). Previous studies have reported that lactic acid can be converted to butyric acid by butyrate bacteria (Bourriaud et al., 2005, Louis and Flint, 2009). Therefore, high concentrations of butyric acid in GS may be related to Clostridium butyricum. Moreover, sufu also contained propionic acid. Song et al. (2021) also detected propionic acid in grey sufu and indicated that excessive intake of propionic acid would lead to vomiting, nausea and other symptoms. Chinese national standard GB 2760-2014 stipulates that the content of propionic acid in bean products shall not exceed $2.5 \mathrm{~g} / \mathrm{kg}$. In this study, the content of propionic acid in sufu was low. So, eating a small amount of sufu will not cause harm to human body. The content of indole in sufu was different from that reported by Huang et al. (2018). In addition, Huang et al. (2018) also found that the synthesis of indole in sufu was related to Weissella and Lactococcus. Previous studies have shown that there were some same microorganisms in various sufu, but their abundance was obviously different (Tan et al., 2020). Therefore, the content of flavor substances in sufu is also different. Sufu is a complex food matrix and its flavor will be affected by raw materials, microorganisms, processing technology and other factors.

Compared with WS, the level of total free amino acid in RS was lower, which was also the same case in the report of Tan et al. (2020). Xie et al. (2019b) showed that the content of bitter and umami amino acids in different sufu were rich and the highest detectable amount bitter amino acids in grey sufu was Leu. The results of this study were similar. The formation of these bitter amino acids may be related to the imbalance of protein and peptide hydrolysis. Some studies have pointed out that there is an interaction between bitterness and freshness. When Phe (0.5-5.0 $\mathrm{mM})$ was added, the umami tastes can 
significantly improved (Chen and Zhang, 2007, Kim et al., 2015). Therefore, Phe in sufu will affect its umami characteristics to a certain extent. The interaction between different amino acids also affects the flavor characteristics of sufu (Lioe et al., 2005).

Electronic nose and electronic tongue had different identification effects on various productions. Chen et al. (2018) research showed that jujubes could be classification by E-nose technology combined with multivariate statistical analysis. It shows that the electronic nose has certain applicability in the differentiation of products. Xing et al. (2021) distinguished the processing degree of Polygonum multiflorum using electronic tongue. In addition, some studies also showed that the electronic tongue technology can be applied to milk, meat and so on (Di Rosa et al., 2017). In this study, the electronic tongue has an obvious effect on distinguishing all kinds of sufu, but the electronic nose can only distinguish GS. GS contained some volatile components with strong irritation, such as indole and sulfide, which were significantly different from other types of sufu. Therefore, the electronic nose was easier to distinguish grey sufu. In addition, Di Donato et al. (2021) showed also volatile substances (obtained by HS-SPME/GC-MS) coupled with PLS-DA was effective in the discrimination of typical Italian Pecorino cheeses. Meanwhile, fourteen components related to the discrimination of the Pecorino cheeses were screened by VIP value. This experiment also used this method to reach the aim of distinguished the types of sufu.

\section{Conclusion}

The present study revealed the volatile flavor compounds of five kinds of sufu by HS-SPME/GC-MS method. The flavor characteristics of different sufu were diversities. The total content of volatile flavor compounds in GS was the highest, followed by LS and the lowest in WS. Esters were the most abundant flavor substances in all sufu samples, which had a higher contribution to the sufu characteristic flavors. Evaluation of amino acid profiles from commercial sufu demonstrated that Glu, Val, Leu and Phe were high content taste amino acids in sufu. Compared with other sufu, GS has the defect of insufficient umami. PCA combined with electronic tongue could accurately discriminate all kinds of sufu. In contrast, the electronic nose could only distinguish grey sufu. The PLS-DA analysis based on volatile components and flavor amino acids could clearly distinguish five different types of sufu and differential compounds were screened, such as nonanal, phenyl ethanol, 2,2,4trimethyl-1,3-pentanediol diisobutyrate, anisaldehyde, Met, Phe, Ser, Tyr and Lys. In summary, when the specific components are known, PLS-DA analysis can accurately distinguish various samples from the perspective of aroma and taste to achieve the purpose of identification. When the specific components are unknown, electronic tongue is more suitable for distinguishing various types of sufu. In order to ensure the reliability of the experimental results, electronic tongue combined with HS-SPME/GC-MS technology can be used. These results are applicable to the quality control of sufu and the development of new products, which is beneficial to the development of sufu industry. The effect of microorganisms on the flavor of sufu was not analyzed in this study. After that, we can further study the core microbial flora of sufu and screen out the strains related to flavor, which are particularly important for standardized sufu production.

\section{Funding Information}

This study was funded by the Natural Science Foundation of China (Grant No. 31601462); Henan Key Laboratory of Industrial Microbial Resources and Fermentation Technology, Open Foundation, China, Nanyang, (Grant No. HIMFT20190307 and HIMFT20190308).

\section{Author's Contributions}

Xiaoli Xi: Has contributed in all experiments, paper writing and publication.

Yanli Ma and Jingxuan Ke: Have contributed in the paper writing, reviewed and revised the manuscript.

Yinzhuang Wang and Xiaodong Gu: Have assisted in the experiment.

Yaqiong Liu, Jianfeng Sun and Jianlou Mu: Has organized the study, reviewed and revised the manuscript.

\section{Ethics}

This article is original and contains unpublished material. The corresponding author confirms that all of the other authors have read and approved the manuscript and no ethical issues involved.

\section{References}

Ardo, Y. (2006). Flavour formation by amino acid catabolism. Biotechnol Adv, 24 (2), 238-242. doi.org/10.1016/j.biotechadv.2005.11.005

Bourriaud, C., Robins, R. J., Martin, L., Kozlowski, F., Tenailleau, E., Cherbut, C., \& Michel, C. (2005). Lactate is mainly fermented to butyrate by human intestinal microfloras but inter-individual variation is evident. Journal of Applied Microbiology, 99 (1), 201-212. doi.org/10.1111/j.1365-2672.2005.02605.x

Chen, D. W., \& Zhang, M. (2007). Non-volatile taste active compounds in the meat of Chinese mitten crab (Eriocheir sinensis). Food Chemistry, 104 (3), 1200-1205. doi.org/10.1016/j.foodchem.2007.01.042 
Chen, Q. Q., Song, J. X., Bi, J. F., Meng, X. J., \& Wu, X. Y. (2018). Characterization of volatile profile from ten different varieties of Chinese jujubes by HSSPME/GC-MS coupled with E-nose. Food Research International, 105, 605-615. doi.org/10.1016/j.foodres.2017.11.054

Chen, S., Xu, Y., \& Qian, M. C. (2013). Aroma characterization of Chinese rice wine by gas chromatography-olfactometry, chemical quantitative analysis and aroma reconstitution. Journal of Agricultural and Food Chemistry, 61 (47), 11295-11302. doi.org/10.1021/jf4030536

Chung, H. Y. (2000). Volatile flavor components in red fermented soybean (Glycine max) curds. Journal of Agricultural and Food Chemistry, 48 (5), 1803-1809. doi.org/10.1021/jf991272s

Di Donato, F., Biancolillo, A., Mazzulli, D., Rossi, L., \& D'Archivio, A. A. (2021). HS-SPME/GC-MS volatile fraction determination and chemometrics for the discrimination of typical Italian Pecorino cheeses. Microchemical Journal, 165. doi.org/10.1016/j.microc.2021.106133

Di Rosa, A. R., Leone, F., Cheli, F., \& Chiofalo, V. (2017). Fusion of electronic nose, electronic tongue and computer vision for animal source food authentication and quality assessment - A review. Journal of Food Engineering, 210, 62-75. doi.org/10.1016/j.jfoodeng.2017.04.024

Dong, W. J. R., Hu, R. S., Long, Y. Z., Li, H. H., Zhang, Y. J., Zhu, K. X., \& Chu, Z. (2019). Comparative evaluation of the volatile profiles and taste properties of roasted coffee beans as affected by drying method and detected by electronic nose, electronic tongueand HS-SPME-GC-MS. Food Chemistry, 272, 723-731. doi.org/10.1016/j.foodchem.2018.08.068

Durguti, V., Aliu, S., Laha, F., \& Feka, F. (2020). Determination of iron, copper and zinc in the wine by FAAS. Emerging Science Journal, 4 (5), 411-417. doi.org/10.28991/esj-2020-01240

Fan, X. J., Liu, G. F., Qiao, Y. L., Zhang, Y. J., Leng, C., Chen, H. Y., Sun, J. H., \& Feng, Z. (2019). Characterization of volatile compounds by SPMEGC-MS during the ripening of Kedong Sufu, a typical Chinese traditional bacteria-fermented soybean product. Journal of Food Science, 84 (9), 2441-2448. doi.org/10.1111/1750-3841.14760

Han, B. Z., Rombouts, F. M., \& Nout, M. J. R. (2001). A Chinese fermented soybean food. International Journal of Food Microbiology, 65 (1-2), 1-10. doi.org/10.1016/s0168-1605(00)00523-7

Han, B. Z., Rombouts, F. M., \& Nout, M. J. R. (2004). Amino acid profiles of sufu, a Chinese fermented soybean food. Journal of Food Composition and Analysis, 17 (6), 689-698.

doi.org/10.1016/j.jfca.2003.09.012
Huang, X. N., Yu, S. Z., Han, B. Z., \& Chen, J. Y. (2018). Bacterial community succession and metabolite changes during sufu fermentation. LWT-Food Science and Technology, 97, 537-545. doi.org/10.1016/j.lwt.2018.07.041

Hwan, C. H., \& Chou, C. C. (1999). Volatile components of the Chinese fermented soya bean curd as affected by the addition of ethanol in ageing solution. Journal of the Science of Food and Agriculture, 79 (2), 243-248. doi.org/10.1002/ (SICI) 1097-0010(199902)79:23.0.CO; 2-I

Ji, X. Y. (2020). Investigation of the volatile components in commercial sufu (Chinese fermented soybean curd) based on HS-SPME/GC-MS combined with multivariate statistical analysis. Journal of Food Processing and Preservation, 44 (1). doi.org/10.1111/jfpp.14309

Kim, M. J., Son, H. J., Kim, Y., Misaka, T., \& Rhyu, M. R. (2015). Umami-bitter interactions: The suppression of bitterness by umami peptides via human bitter taste receptor. Biochemical and Biophysical Research Communications, 456 (2), 586-590. doi.org/10.1016/j.bbrc.2014.11.114

Li, Z., Dong, L., Huang, Q., \& Wang, X. (2016). Bacterial communities and volatile compounds in Doubanjiang, a Chinese traditional red pepper paste. Journal of Applied Microbiology, 120 (6), 1585-1594. doi.org/10.1111/jam. 13130

Liang, J. J., Li, D. W., Shi, R. Q., Wang, J., Guo, S., Ma, Y. L., \& Xiong, K. (2019). Effects of microbial community succession on volatile profiles and biogenic amine during sufu fermentation. LWT-Food Science and Technology, 114. doi.org/10.1016/j.lwt.2019.108379

Lioe, H. N., Apriyantono, A., Takara, K., Wada, K., \& Yasuda, M. (2005). Umami taste enhancement of $\mathrm{MSG} / \mathrm{NaCl}$ mixtures by subthreshold L-alphaaromatic amino acids. Journal of Food Science, 70 (7), S401-S405. doi.org/10.1111/j.1365-2621.2005.tb11483.x

Liu, H., Wang, Z. Y., Zhang, D. Q., Shen, Q. W., Pan, T. Hui, T., \& Ma, J. R. (2019). Characterization of key aroma compounds in Beijing Roasted Duck by cas chromatography-olfactometry-mass spectrometry, odor-activity values and aroma-recombination experiments. Journal of Agricultural and Food Chemistry, 67 (20), 5847-5856. doi.org/10.1021/acs.jafc.9b01564

Liu, S. Q., Holland, R., \& Crow, V. L. (2004). Esters and their biosynthesis in fermented dairy products: A review. International Dairy Journal, 14 (11), 923-945. doi.org/10.1016/j.idairyj.2004.02.010

Liu, Y. P., Miao, Z. W., Guan, W., \& Sun, B. G. (2012). Analysis of organic volatile flavor compounds in fermented stinky tofu using SPME with different fiber coatings. Molecules, 17 (4), 3708-22. doi.org/10.3390/molecules 17043708 
Louis, P., \& Flint, H. J. (2009). Diversity, metabolism and microbial ecology of butyrate-producing bacteria from the human large intestine. Fems Microbiology Letters, 294 (1), 1-8. doi.org/10.1111/j.1574-6968.2009.01514.x

Loutfi, A., Coradeschi, S., Mani, G. K., Shankar, P., \& Rayappan, J. B. B. (2015). Electronic noses for food quality: A review. Journal of Food Engineering, 144, 103-111. doi.org/10.1016/j.jfoodeng.2014.07.019

Moy, Y. S., Lu, T. J., \& Chou, C. C. (2012). Volatile components of the enzyme-ripened sufu, a Chinese traditional fermented product of soy bean. Journal of Bioscience and Bioengineering, 113 (2), 196-201. doi.org/10.1016/j.jbiosc.2011.09.021

Nkansah, M. A., Donkoh, M., Akoto, O., \& Ephraim, J. H. (2019). Preliminary Studies on the Use of Sawdust and Peanut Shell Powder as Adsorbents for Phosphorus Removal from Water. Emerging Science Journal, 3 (1), 33. doi.org/10.28991/esj-2019-01166

Parker, J. K., Lignou, S., Shankland, K., Kurwie, P., Griffiths, H. D., \& Baines, D. A. (2018). Development of a Zeolite Filter for Removing Polycyclic Aromatic Hydrocarbons (PAHs) from Smoke and Smoked Ingredients while Retaining the Smoky Flavor. Journal of Agricultural and Food Chemistry, 66 (10), 2449-2458. doi.org/10.1021/acs.jafc.6b05399

Peng, X. Y., Li, X., Shi, X. D., \& Guo, S. T. (2014). Evaluation of the aroma quality of Chinese traditional soy paste during storage based on principal component analysis. Food Chem, 151, 532-8. doi.org/10.1016/j.foodchem.2013.11.095

Smit, B. A., Engels, W. J. M., \& Smit, G. (2009). Branched chain aldehydes: Production and breakdown pathways and relevance for flavour in foods. Applied Microbiology and Biotechnology, 81 (6), 987-999. doi.org/10.1007/s00253-008-1758-X

Song, Z. Y., Hu, Y. Z., Chen, X., Li, G. H., Zhong, Q. D., He, X. Y., \& Xu, W. T. (2021). Correlation between bacterial community succession and propionic acid during gray sufu fermentation. Food Chemistry, 353. doi.org/10.1016/j.foodchem.2021.129447

Souayah, F., Rodrigues, N., Veloso, A. C. A., Dias, L. G., Pereira, J. A., Oueslati, S., \& Peres, A. M. (2017). Discrimination of olive oil by cultivar, geographical origin and quality using potentiometric electronic tongue fingerprints. Journal of the American Oil Chemists Society, 94 (12), 1417-1429. doi.org/10.1007/s11746-017-3051-6

Sunday, N. F. (2020). Chemometrics of solvent extraction of $\mathrm{Mn}(\mathrm{II})$ and $\mathrm{Fe}(\mathrm{III})$ bis(salicylidene) ethylenediamine complexes in acid medium. Journal of Human, Earth and Future, 1 (2), 71-77. doi.org/10. 28991/HEF-2020-01-02-03
Tan, G. L., Hu, M., Li, X. Y., Pan, Z. Q., Li, M., Li, L., \& Yang, M. X. (2020). High-throughput sequencing and metabolomics reveal differences in bacterial diversity and metabolites between red and white Sufu. Frontiers in Microbiology, 11. doi.org/10.3389/fmicb.2020.00758

Thammarongtham, C., Turner, G., Moir, A. J., Tanticharoen, M., \& Cheevadhanarak, S. (2001). A new class of glutaminase from Aspergillus oryzae. Journal of Molecular Microbiology and Biotechnology, 3 (4), 611-617.

Umana, U. S., Ebong, M. S., \& Godwin, E. O. (2020). Biomass production from oil palm and its value chain. Journal of Human, Earth and Future, 1 (1), 30-38. doi.org/10. 28991/HEF-2020-01-01-04

Wang, P., Ma, X. R., Wang, W. P., Xu, D. D., Zhang, X., Zhang, J., \& Sun, Y. (2019). Characterization of flavor fingerprinting of red sufu during fermentation and the comparison of volatiles of typical products. Food Science and Human Wellness, 8 (4), 375-384. doi.org/10.1016/j.fshw.2019.11.004

Wei, G. M., Regenstein, J. M., \& Zhou, P. (2021). The aroma profile and microbiota structure in oil furu, a Chinese fermented soybean curd. Food Research International, 147. doi.org/10.1016/j.foodres.2021.110473

Xie, C. Z., Zeng, H. Y., Li, J. W., \& Qin, L. K. (2019a). Comprehensive explorations of nutritional, functional and potential tasty components of various types of Sufu, a Chinese fermented soybean appetizer. Food Science and Technology, 39 (suppl 1), 105-114. doi.org/10.1590/fst.37917

Xie, C. Z., Zeng, H. Y., Wang, C. X., Xu, Z. M., \& Qin, L. K. (2018). Volatile flavour components, microbiota and their correlations in different sufu, a Chinese fermented soybean food. Journal of Applied Microbiology, 125 (6), 1761-1773. doi.org/10.1111/jam.14078

Xie, M. X., An, F. Y., Yue, X. Q., Liu, Y. M., Shi, H. S., Yang, M., Cao, X. Y., Wu, J. R., \& Wu, R. N. (2019b). Characterization and comparison of metaproteomes in traditional and commercial dajiang, a fermented soybean paste in northeast China. Food Chemistry, 301. doi.org/10.1016/j.foodchem.2019.125270

Xing, Y. C., Yan, Z., Li, Y. H., Teka, T., Pan, G. X., Dou, Z. Y., Gao, X. M., He, J. and Han, L. F. (2021). An effective strategy for distinguishing the processing degree of fPolygonum multiflorum based on the analysis of substance and taste by LCMS, ICP-OES and electronic tongue. Journal of Pharmaceutical and Biomedical Analysis, 205. doi.org/10.1016/j.jpba.2021.114328 
Yoon, Y. E., Kuppusamy, S., Cho, K. M., Kim, P. J., Kwack, Y. B. and Lee, Y. B. (2017). Influence of cold stress on contents of soluble sugars, vitamin C and free amino acids including GammaAminobutyric Acid (GABA) in spinach (Spinacia oleracea). Food Chem, 215, 185-92. doi.org/10.1016/j.foodchem.2016.07.167

Yu, A. N., Sun, B. G., Tian, D. T., \& Qu, W. Y. (2008). Analysis of volatile compounds in traditional smokecured bacon (CSCB) with different fiber coatings using SPME. Food Chemistry, 110 (1), 233-238. doi.org/10.1016/j.foodchem.2008.01.040
Zhao, C. J., Schieber, A., \& Gaenzle, M. G. (2016).

Formation of taste-active amino acids, amino acid derivatives and peptides in food fermentations - A review. Food Research International, 89, 39-47. doi.org/10.1016/j.foodres.2016.08.042

Zheng, J., Liang, R., Zhang, L. Q., Wu, C. D., Zhou, R. Q., \& Liao, X. P. (2013). Characterization of microbial communities in strong aromatic liquor fermentation pit muds of different ages assessed by combined DGGE and PLFA analyses. Food Research International, 54 (1), 660-666.

doi.org/10.1016/j.foodres.2013.07.058 